\title{
Vertebral compression fractures: a review of current management and multimodal therapy
}

This article was published in the following Dove Press journal:

Journal of Multidisciplinary Healthcare

14 June 2013

Number of times this article has been viewed

\section{Cyrus CWong}

Matthew J McGirt

Vanderbilt University Medical Center, Nashville, TN, USA
Correspondence: Cyrus C Wong

Department of Neurological Surgery,

Vanderbilt University Medical Center,

II6I 2 Ist Avenue South, T4224 MCN,

Nashville, TN 37232-2380, USA

Tel +l 6153432452

Fax + I 6153438104

Email cyrus.c.wong@vanderbilt.edu
Abstract: Vertebral compression fractures are a prevalent disease affecting osteoporotic patients. When symptomatic, they cause significant pain and loss of function and have a high public health impact. In this paper we outline the diagnosis and management of these patients, with evidence-based review of treatment outcomes for the various therapeutic options. Diagnosis involves a clinical history focusing on the nature of the patient's pain as well as various imaging studies. Management is multimodal in nature and starts with conservative therapy consisting of analgesic medication, medication for osteoporosis, physical therapy, and bracing. Patients who are refractory to conservative management may be candidates for vertebral augmentation through either vertebroplasty or kyphoplasty.

Keywords: vertebral compression fractures, osteoporosis, bracing, vertebroplasty, kyphoplasty

\section{Epidemiology and public health impact Epidemiology and risk factors}

Vertebral compression fractures are the most common sequelae of osteoporosis, comprising approximately 700,000 out of a total 1.5 million osteoporotic fractures annually in the USA. ${ }^{1}$ The actual incidence of vertebral fractures is likely much greater given the large number of vertebral fractures that go undetected, with only a third of vertebral fractures clinically diagnosed. ${ }^{1-4}$

Vertebral fractures are directly correlated with increasing age and incidence of osteoporosis. They most commonly occur among Caucasian women and are less common among men and women of African-American or Asian ethnicity. ${ }^{1,5,6}$ Bone density of the vertebral column decreases steadily with age, with elderly women having lost almost half their axial bone mass by the time they reach their eighties. ${ }^{7-9}$ The rate of vertebral fractures increases from an annual incidence of $0.9 \%$ and prevalence of $5 \%-10 \%$ among middle-aged women in their $50 \mathrm{~s}$ to $60 \mathrm{~s}$, to an incidence of $1.7 \%$ and prevalence of greater than $30 \%$ among those 80 years and older. ${ }^{1,10,11}$ These agecorrelated prevalence rates in the USA are very similar to those in Europe as published by the European Vertebral Osteoporosis Study. ${ }^{3,12}$

The risk of developing a vertebral fracture is strongly associated with decreasing bone density, with the risk increasing roughly two times for every standard deviation below average vertebral bone mineral density. ${ }^{1,3}$ Bone density begins to decrease after age 40 for both men and women, and the process is rapidly accelerated in postmenopausal women. Though genetic predisposition and age of puberty onset play 
a significant role, a multitude of lifestyle and environmental factors increase the risk of developing osteoporosis. These include lack of exercise and low body mass index, insufficient dietary calcium, low vitamin D production, glucocorticoid medication, smoking, and excessive alcohol intake. ${ }^{1,3,13}$ Occasionally, vertebral compression fractures may be the presenting finding for an underlying medical condition such as metastatic disease or hyperparathyroidism.

Though most commonly found among osteoporotic patients ( $T$ score $\leq-2.5$ on dual-energy x-ray absorptiometry [DEXA]), vertebral fractures may also occur in up to $18 \%$ of women $>60$ years old with low bone mass but not meeting the criteria for osteoporosis ( $\mathrm{T}$ score $>-2.5$ but $<-1.4$ ). ${ }^{1,14}$ It is estimated that more than a third of postmenopausal vertebral compression fractures occur in women who do not meet the criteria for osteoporosis. ${ }^{1,15}$

Furthermore, the risk of developing a vertebral fracture is roughly five times greater if the patient has had a prior fracture, and $20 \%$ of osteoporotic postmenopausal women who present with an initial vertebral fracture develop a subsequent vertebral fracture within the year. ${ }^{16,17}$ These patients are also at high risk of developing other significant osteoporotic fractures, such as hip fractures, ${ }^{3}$ highlighting the need for early detection, treatment, and medical optimization of a patient's bone quality and health.

\section{Socioeconomic costs}

Vertebral fracture, when symptomatic through either back pain or occasionally neurologic compromise, is a high impact disease with significant societal and economic costs. The annual US medical cost for vertebral fracture management was estimated at $\$ 13.8$ billion in $2001^{18,19}$ and has likely since increased with the growing elderly population. ${ }^{20}$ The total economic cost is also far greater than the cost for acute management given that vertebral fractures can lead to significant long-term morbidity. In the first year alone after a painful vertebral fracture, patients have been found to require primary care services at a rate 14 times greater than the general population. ${ }^{3,21}$ Furthermore, osteoporotic compression fractures have been associated with a $15 \%$ higher mortality rate. ${ }^{22}$

\section{Diagnosis and symptoms Clinical presentation}

Many fractures may develop insidiously and chronic compression fractures are commonly detected incidentally on chest X-rays. ${ }^{23}$ When symptomatic, patients complain of sudden-onset severe, focal, back pain that may radiate anteriorly and be confused with a cardiac or pulmonary process. ${ }^{3}$ The vertebral bodies support $80 \%$ of the body's weight, ${ }^{9}$ so that the pain is typically worse when sitting up, standing, or ambulating, and improved when lying down. This is described as mechanical axial back pain, and can be distinguished through history taking from other etiologies of back pain such as osteoarthritic pain, pathologic pain associated with tumor, and lumbar strain.

Vertebral compression fractures usually occur in the mid-thoracic or thoracolumbar transition zone of the spine. Though exceedingly rare, occasionally retropulsion of fracture fragments may result in compression of the spinal cord or cauda equina and result in weakness and loss of sensation of the lower extremities or even bowel or bladder incontinence. Depending on the severity and rapidity of deficit onset, this may constitute a surgical emergency. ${ }^{24}$

The loss of height that results from a compression fracture may lead to kyphotic deformity of the spine, especially for multiple compression fractures with significant height loss. This may result in focal or global sagittal imbalance, which may lead to chronic back pain even after the fracture has healed and accelerate the degeneration of adjacent spinal segments. The back pain and associated fatigue can severely limit a patient's quality of life and ability to perform activities of daily living. In addition, severe kyphoscoliotic deformity can even lead to a restricted abdominal space, limiting pulmonary vital capacity as well as decreasing nutritional intake, thus compounding patient immobility.

\section{Imaging}

Many imaging studies may be used in the workup of vertebral compression fractures. The most widely available and costeffective initial imaging study is a lateral X-ray of the thoracic or lumbar spine (Figure 1). This allows for quick screening and identification of fractures, estimation of loss of height and, when taken upright, assessment of spinal alignment. Certain characteristics on plain radiograph are suggestive of osteopenia: increased lucency, loss of horizontal trabeculae, and decreased cortical thickness but increased relative opacity of the end-plates and vertical trabeculae. ${ }^{25}$ Comparison to preexisting spine X-rays allows the clinician to diagnose and judge the age of the vertebral fracture. In patients without prior spinal imaging, certain radiographic criteria may aid in diagnosis. Compression fractures may be classified based on the portion of the vertebral body that is affected: either wedge-shaped (anterior), biconcave (middle), or crush (posterior), with a minimum of $20 \%$ height loss relative to the unaffected portion of the vertebral body. ${ }^{26}$ In cases of 


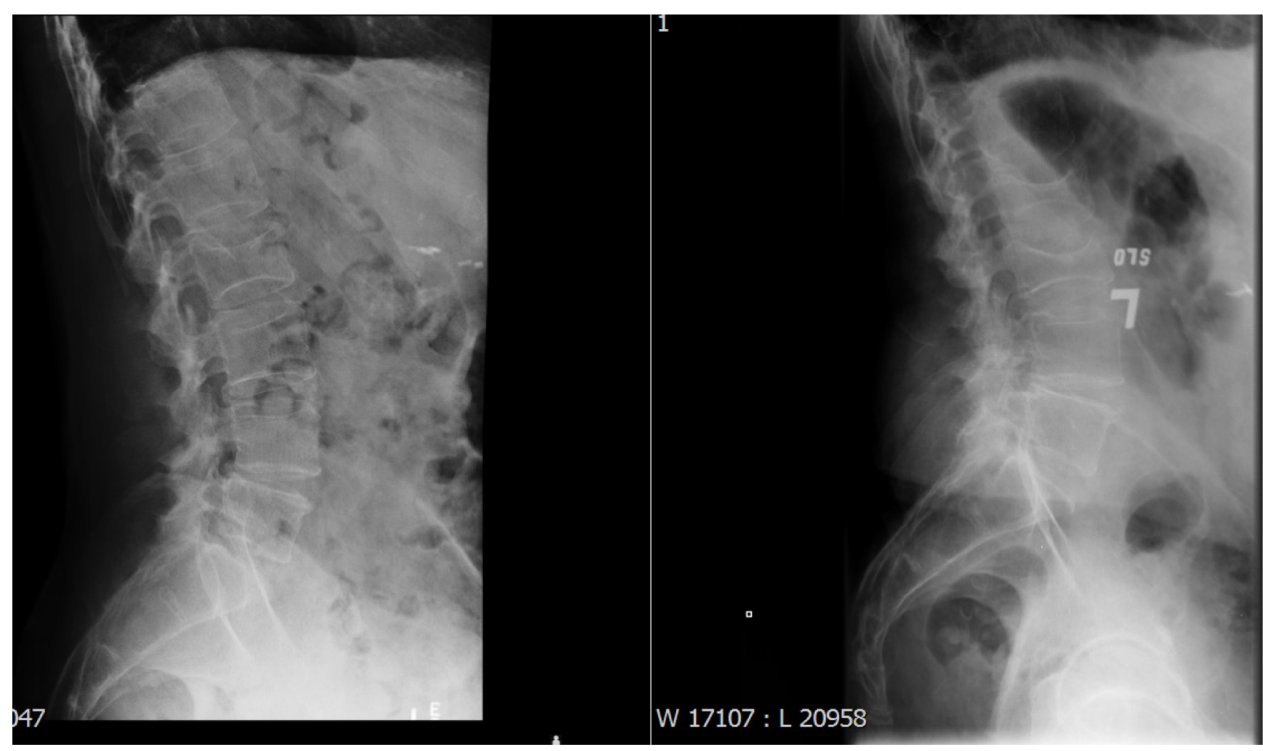

Figure I Lateral radiograph demonstrates biconcave-appearing compression fractures at L2 and L3, showing progression in loss of height in these X-rays taken a year apart.

complete compression fractures there is a reduction in both posterior and anterior height. ${ }^{9}$ A plain radiograph may be all that is necessary for a majority of compression fractures, especially if one proceeds with conservative, medical management.

When there is need for further characterization, a computed tomography (CT) scan allows for the best imaging of bony anatomy and improved assessment of loss of height, fragment retropulsion, and canal compromise. However, this comes with greater expense and irradiation for the patient. CT scan may also reveal a chronic fracture through the presence of cortication. However, magnetic resonance imaging (MRI) is the best study for judging fracture age, as it will show bony edema for an acute fracture. In addition, MRI allows for the evaluation of neural compromise secondary to compression of the spinal cord or nerve roots (Figure 2). MRI short TI inversion recovery (STIR) sequence will also reveal integrity of the spinal ligamentous complex, which can be important during surgical evaluation of fracture stability. Finally, a postcontrast MRI study will detect a pathologic fracture secondary to an oncologic process. Other, less commonly used imaging studies include bone scan (Figure 3), which will show increased uptake in a fracture, ${ }^{27}$ or vertebral fracture assessment, which allows for a quick fracture evaluation from T4 to L4 and may be done in conjunction with a DEXA scan. ${ }^{1}$

\section{Bone density assessment}

Without a history of trauma, spontaneous vertebral compression fractures are typically pathognomonic for osteoporosis. After the diagnosis of a compression fracture on initial imaging, bone density should be assessed by DEXA scan. Bone density on DEXA is reported as a $\mathrm{T}$ score and is typically measured at several sites including the spine, hip, and femoral neck to avoid being thrown off by local variations secondary to osteoarthritis. Roughly half of patients with vertebral fractures have osteoporosis ( $\mathrm{T}$ score $<-2.5$ ) and another $40 \%$ have osteopenia ( $\mathrm{T}$ score -1 to -2.5 ), ${ }^{3}$ and medical treatment aimed at improving bone quality should be initiated in these patients.

\section{Medical management Pain control}

Following initial evaluation and diagnosis of a vertebral compression fracture, therapy should be aimed at pain control in a manner that avoids prolonged bed-rest and allows for early mobilization of the patient. Acute pain control may include nonsteroidal anti-inflammatory drugs (NSAIDs), muscle relaxants, narcotic pain medication, neuropathic pain agents (ie, tricyclic antidepressants), local analgesic patch, intercostal nerve blocks, and transcutaneous nerve stimulation units. ${ }^{1,3}$ NSAIDs are often first-line drugs for back pain as they do not have sedating effects. However, they do have gastric toxicity and an increased risk of cardiac events for patients with hypertension and coronary artery disease. ${ }^{28}$ There is also a theoretical inhibitory effect of NSAIDs on bony healing, though this has not been the case in actual studies. ${ }^{29,30}$ Opioids and muscle relaxants may provide strong relief when NSAIDs are inadequate but have significant 


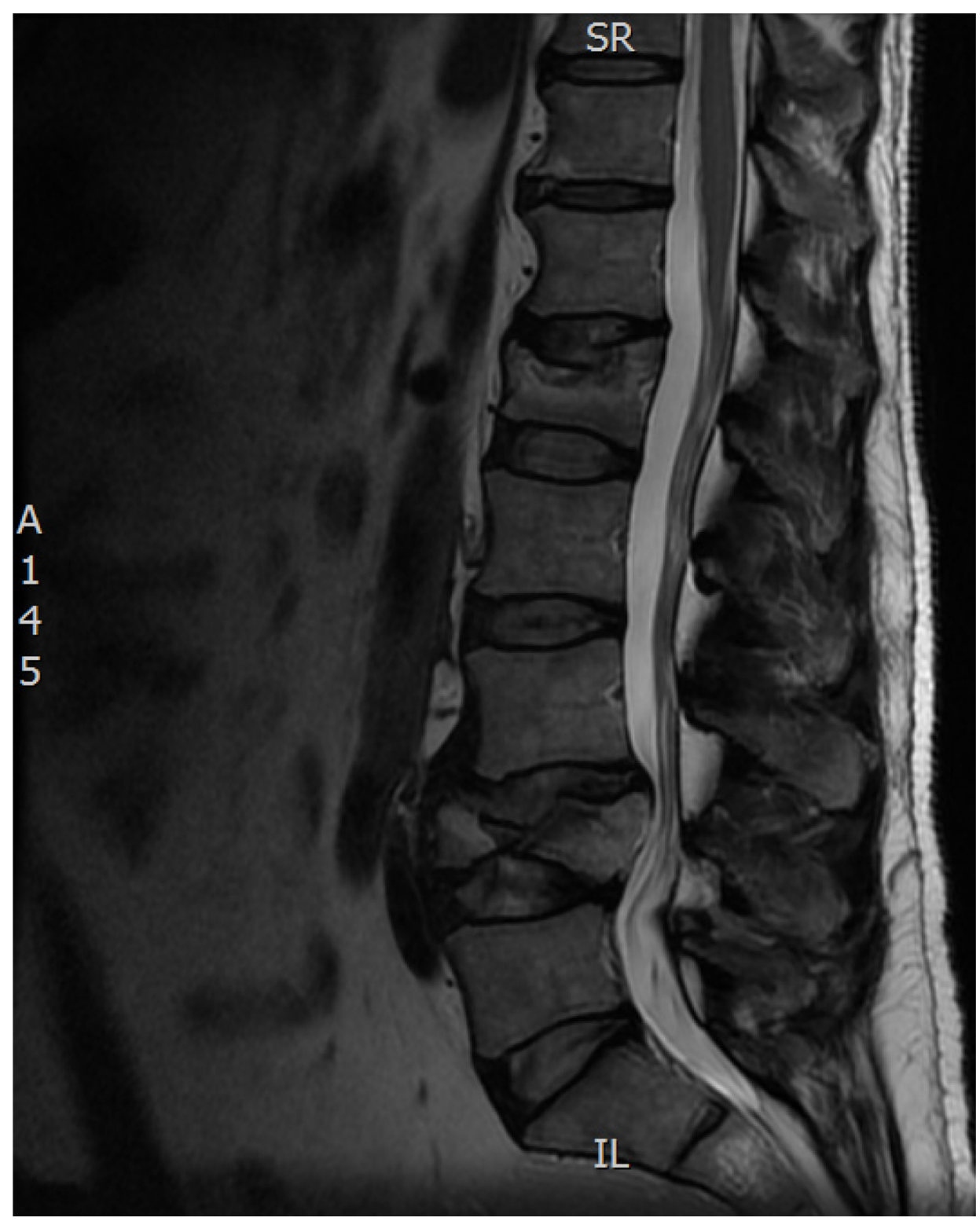

Figure 2 Sagittal T2 magnetic resonance imaging demonstrating a traumatic burst fracture at L4 with bony retropulsion and canal compromise requiring open surgical decompression and fixation.

Note: A concomitant acute compression fracture at LI (note the bony edema) was treated with kyphoplasty in the same surgery.

sedative effects as well as the risk of dependency. As such their use needs to be carefully balanced in the geriatric patient. $^{3}$

\section{Preventative medicine}

Other than acute pain control, medical therapy should be aimed at improving bone quality and thus reducing the risk of future fracture. Agents for treating osteoporosis include bisphosphonates, selective estrogen receptor modulators, recombinant parathyroid hormone, and calcitonin. These agents act through either antiresportive or osteogenic mechanisms. ${ }^{3}$ The bisphosphonate alendronate is a first-line medication given its favorable safety profile and efficacy in reducing fracture risk. ${ }^{1}$ Hormone replacement therapy may be an option for younger postmenopausal women. ${ }^{3}$ Finally, while calcium and vitamin D are insufficient alone in reducing fracture risk, supplementation may be necessary for deficient patients. Follow up of treatment efficacy may be done with subsequent DEXA scan, though typically a 2-year treatment period is needed before improvement of bone mineral density is detected. ${ }^{3}$

Interestingly, several medications for osteoporosis treatment also play a role in acute pain relief. ${ }^{30}$ Calcitonin has been found in multiple randomized controlled trials 


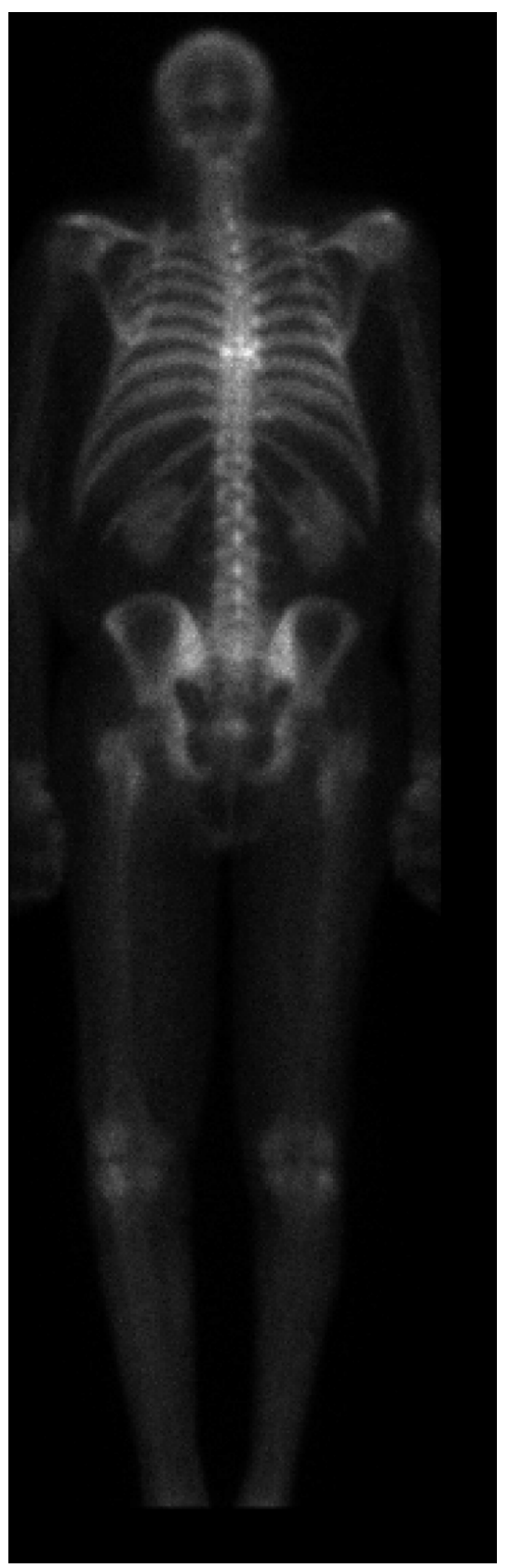

Figure 3 Nuclear medicine bone scan demonstrating increased uptake at a T7 fracture.

to provide pain relief for acute compression fractures. ${ }^{31}$ Bisphosphonates have also shown similar improvements in acute pain control..$^{32}$ Finally, patients treated with teriparatide (recombinant parathyroid hormone) show decreased back pain, when compared with patients treated with placebo, hormone replacement therapy, or alendronate. ${ }^{33,34}$

\section{Physical therapy}

Physical therapy should assist with early mobilization in the acute phase and prevent further injuries in the long term. As such, the exercises prescribed should have two purposes: (1) strengthening the patient's supportive axial musculature, in particular the spinal extensors, and (2) training the patient's proprioceptive reflexes to improve posture and ambulation and decrease the likelihood of future falls.

The erector spinae play a crucial role in the posterior tension band that maintains normal posture, by balancing the biomechanical tendency of the spine to fall forward. This function coincidentally reduces mechanical stress on the vertebral bodies. As such, strengthening the spinal extensor muscles will improve lumbar lordosis and posture, ${ }^{35}$ thus reducing acute fracture pain as well as chronic back pain associated with kyphotic deformity. This reinforcement is especially important since axial musculature decreases in strength with age, particularly among women ${ }^{36}$ who are most at risk for vertebral fracture. Studies have shown that back extension strength and lumbar mobility are the most important factors for quality of life among postmenopausal osteoporotic women, compared to other relevant factors such as lumbar kyphosis angle and bone mineral density. ${ }^{37}$

While repetitive mechanical loading will stimulate osteogenesis (Wolff's law) ${ }^{38}$ and improve patient bone quality, such loading parameters need to be within the physiologic capacity of the compromised bone. To that end, both exercise selection and intensity should be tailored towards the individual patient to avoid over-stressing the spine and causing new injury. Intense spinal flexion exercise in any form transmits significant force to the intervertebral discs which, when the discs are degenerated, is largely passed on to the vertebral bodies. ${ }^{9}$ In one study of postmenopausal osteoporotic women undergoing exercise rehabilitation, there was an $89 \%$ rate of further vertebral fracture associated with abdominal flexion training compared to only $16 \%$ with back extension exercises. ${ }^{39}$ Likewise, exercises aimed at increasing spinal flexibility, particularly spinal flexion, may actually reduce some of the protective mechanisms against back pain. ${ }^{40}$ Exercises should focus on strengthening back extension and may include weighted or unweighted prone position extension exercises, isometric contraction of the paraspinal muscles, and careful loading of the upper extremities. $^{41-43}$

The Spinal Proprioception Extension Exercise Dynamic (SPEED) program designed by Sinaki ${ }^{9}$ is an example of a regimen that focuses on strengthening the spinal extensors using a weighted kypho-orthosis and postural and proprioceptive training, through twice-daily, 20-minute exercise sessions. A 4-week program was found to improve 
back pain and back strength, reduce the risk of fall and patient fear of falls, and increase physical activity level. The patients were also shown to have improved gait and posture using computerized analysis. ${ }^{9,44}$

Several other trials have demonstrated similar efficacy of physical therapy programs in managing painful compression fractures. Malmros et al ${ }^{45}$ looked at a 10 -week physiotherapy program involving strength and balance training and found benefits in back extension strength, quality of life, and reduction in pain and analgesic use. These benefits persisted at follow-up 12 weeks after the patients had completed the training program. Bennell et $\mathrm{al}^{46}$ similarly used a 10 -week program that included manual therapy in addition to exercise and demonstrated improved back pain, physical function, and quality of life. Papaioannou et $\mathrm{al}^{47}$ studied a longer, 6-month home exercise program consisting of stretching, strength training, and aerobics and found that the exercise group had improved Osteoporosis Quality of Life Questionnaire scores and improved balance at the 1-year point, though no change in bone mineral density was found.

\section{Bracing}

Bracing is commonly used for symptomatic management of vertebral fractures. However, the majority of randomized controlled trials examining bracing were based on acute, traumatic burst fractures. As such, there is little consensus on its application for osteoporotic compression fractures. One prospective randomized trial on the 6-month use of a thoracolumbar orthoses (TLO) brace for osteoporotic compression fractures found improvement in trunk muscle strength, posture, and body height amongst the treatment group, ultimately with better quality of life and ability to perform activities of daily living (ADL). ${ }^{48}$

The use of a spinal orthosis maintains neutral spinal alignment and limits flexion, thus reducing axial loading on the fractured vertebra. In addition, the brace allows for less fatigue of the paraspinal musculature and muscle spasm relief. ${ }^{30}$ However, this finding has not consistently held up to electromyography study, ${ }^{30}$ with two studies showing increased activity in the spinal muscles with bracing. ${ }^{49,50}$ Several brace types are available depending on the location and severity of fracture. Fractures in the thoracic spine may be treated with TLO. Examples include the Jewitt, cruciform anterior spinal hyperextension, and Taylor brace. ${ }^{30}$ Braces which extend to the sacrum are termed thoracolumbar sacral orthoses. Finally, lumbosacral orthoses are also available for lumbar fractures but are only effective in restricting sagittal plane motion in the upper lumbar spine
(L1-3). Intervertebral motion has been shown to actually increase from L4-S1 with a lumbosacral orthoses brace. ${ }^{51}$

Potential downfalls of a rigid brace include patient discomfort, which may decrease compliance. These patients, typically elderly and frail, are at risk for skin breakdown if the brace edges are not carefully padded. In addition, a brace that is too restrictive may impede the patient's respiratory volume. Finally, with prolonged periods of bracing there is potential for deconditioning and atrophy of the trunk and paraspinal muscles. As such, many authors have moved away from recommending rigid braces ${ }^{3}$ and towards light-weight, soft braces, except in cases of severe deformity.

\section{Surgical management Indications and contraindications}

Though there is no standard time for appropriate conservative management, patients should have pain relief by 6 weeks. When patients continue to have unremitting pain or demonstrated fracture progression on follow-up radiograph, consideration should then be given to a vertebral augmentation procedure. Vertebroplasty and kyphoplasty are minimally invasive, percutaneous procedures performed by spine surgeons and pain management specialists to treat osteoporotic or oncologic fractures.

Eligible patients should have significant back pain and tenderness in the fracture area that increases with mechanical axial loading. The fracture should be within the subacute phase before it is healed. In addition, it is not possible to perform vertebroplasty or kyphoplasty in completely collapsed vertebral bodies, known as vertebra plana. If CT demonstrates incompetency or fracture through the posterior wall of the vertebrae, risk of cement extrusion into the spinal canal is greatly increased. An absolute contraindication is bony retropulsion with neurologic compromise, as this may worsen with the injection of cement. In these cases, an open surgical decompression and fixation may be appropriate. Other contraindications include active osteomyelitis of the fracture site or allergies to kyphoplasty cement. ${ }^{52-54}$ In addition, patients need to tolerate general anesthesia in the prone position (though occasionally sedation and local anesthesia is used). Particular attention needs to be paid to cardiac and pulmonary reserve, especially with treatment of multiple levels, as both operative time and the risk of pulmonary fat embolism increases. ${ }^{55}$

\section{Procedure}

Vertebroplasty involves the fluoroscopically-guided transpedicular insertion of a cannulated trochar that is used to 
inject radiopaque cement, typically polymethylmethacrylate into the fracture. The goal is to provide structural support to the compromised trabecular bone and restore lost vertebral height. Typically a bipedicular approach using two trochars is chosen for more even cement distribution. Occasionally in the upper thoracic spine, where the pedicles can be very small, an extrapedicular approach is used with trochar insertion between the medial rib head and lateral edge of the pedicle..$^{53}$

Ideally two fluoroscopy machines are used simultaneously around the patient, who is positioned in an arms-up "superman" position on a Jackson table, to allow for concurrent anteroposterior (AP) and lateral images. This saves time and reduces the chance of contamination by avoiding the need for frequent fluoroscopy repositioning. A good starting AP image, with the endplates lined up at the procedural level and pedicles clearly outlined, is crucial when introducing the trochars. Subsequently both AP and lateral images are used to guide the advancement of the trochar into the collapsed vertebral body, avoid medial or lateral breaches, and determine the final depth.

Kyphoplasty adds an additional step prior to the cement injection. After trochar insertion, an inflatable balloon tamp is threaded into the fracture and expanded. The purpose of this step is to compact the cancellous bone and create an expanded cavity for cement injection. This plays a significant role in restoring vertebral body height. The extent of inflation is determined by monitoring pressure, inflated volume, and appearance of the balloon and vertebral body on fluoroscopy. Pressure should not exceed a maximum of 300 psi and is usually kept less than 220 psi $^{53}$ Maximum volume inflation ranges from 4-6 mL. During the inflation process sequential images are taken to monitor appropriate expansion of the balloon, ensuring adequate contact with, but avoiding violation of, the cortical endplates (Figure 4). Once the inflation cavity has been created, radiopaque cement is sequentially injected in incremental volumes. It is necessary to take multiple images during injection to ensure that there is adequate cavity filling and no cement retropulsion into the spinal canal (Figure 5).

\section{Potential complications}

Typically vertebral augmentation is performed as an outpatient procedure and is well tolerated. Patients may experience relief of their back pain within 24 hours of the procedure. The overall reported complication rates are particularly low in cases of osteoporotic compression fractures $(<4 \%)$, but increase for oncologic fractures, though symptomatic complications remain less than $10 \%{ }^{18,53,56,57}$ The incidence of cement extravasation into the spinal canal or neuroforamen is rare $(0.4 \%-4 \%)^{18,53}$ and often asymptomatic or transient, but it is important to recognize when this occurs, as it may result in painful radiculopathy and weakness. If high enough to affect the spinal cord or conus medullaris, it may even cause paraparesis, which constitutes an emergency and requires surgical decompression. Cement may also extravasate into the paraspinal musculature, which is typically asymptomatic, but on extremely rare instances may enter the venous system and result in embolic phenomenon. . $^{18,52}$ Finally, fractures may develop in vertebrae adjacent to the augmented vertebral body. Some researchers, for example, Hadley et al, have speculated that this is due to increased loading on the adjacent levels secondary to stiffness of the augmented body ${ }^{58}$ but similar incidences of adjacent fracture with untreated patients have been reported, suggesting that this is a consequence of the patient's existing osteoporotic disease as opposed to a result of the intervention..$^{53}$

\section{Treatment outcomes}

Though a large number of trials have examined the efficacy of vertebral augmentation compared to optimal medical management, there remains significant controversy.
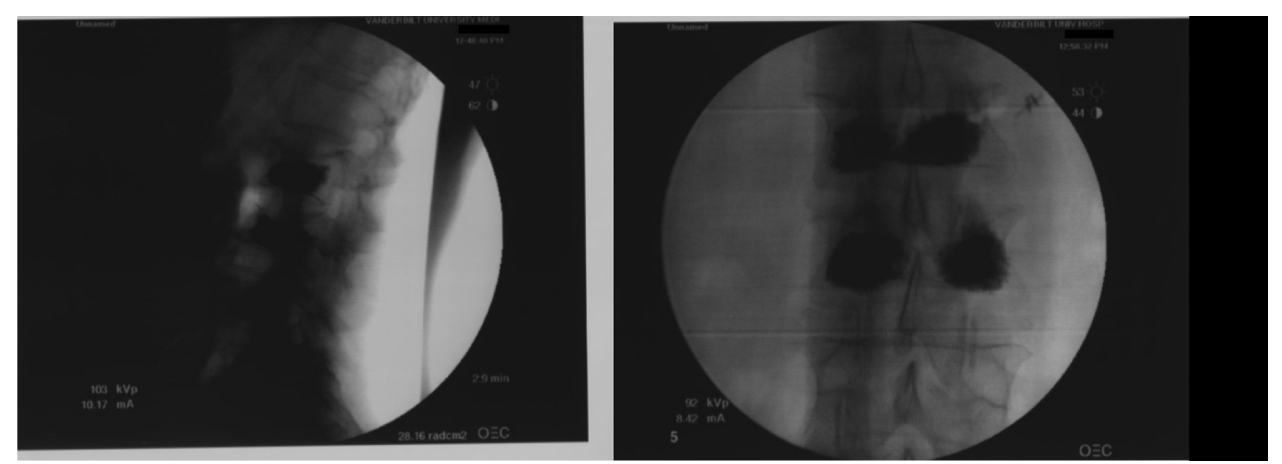

Figure 4 Intraoperative images showing lateral and anteroposterior fluoroscopic images, after the injection of polymethylmethacrylate. 


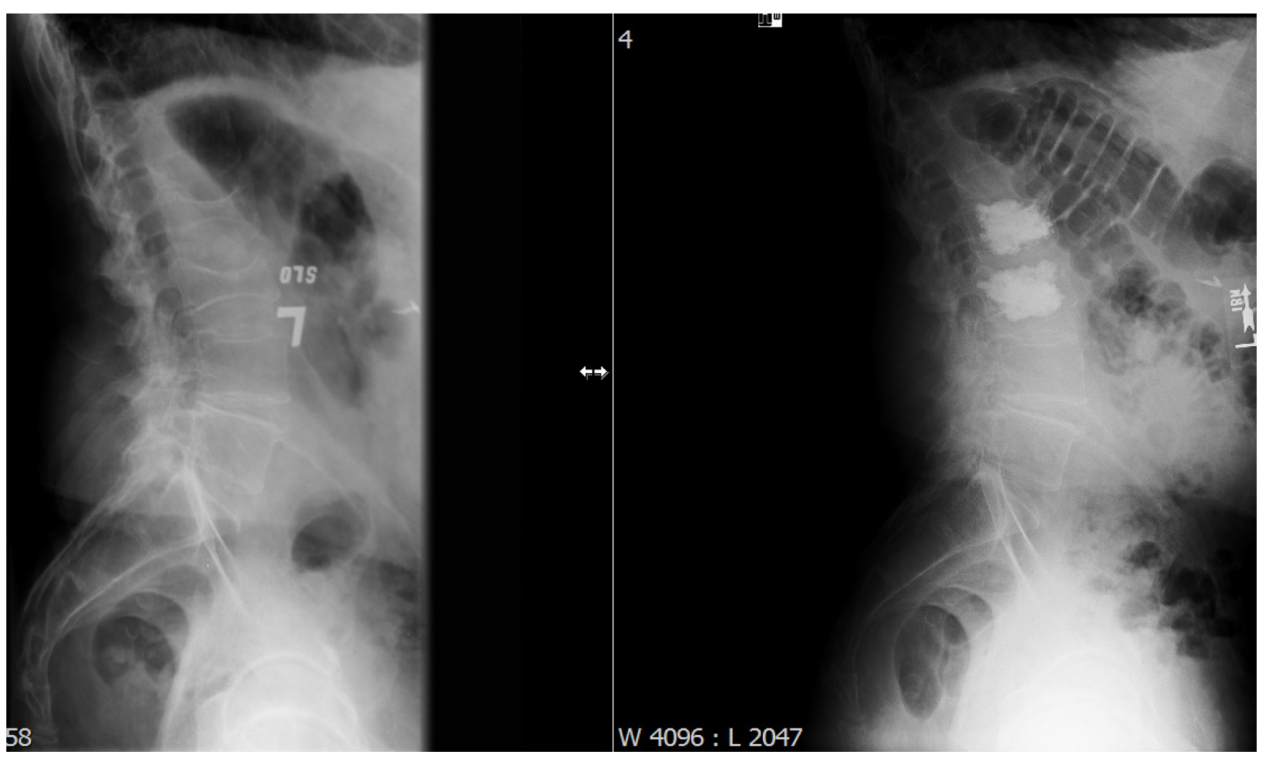

Figure 5 Pre- and postoperative X-rays demonstrating the restoration of vertebral body height after kyphoplasty.

Overall, there are a greater number of studies on vertebroplasty than kyphoplasty given its longer history. McGirt et al published a review in 2009 of all studies of vertebral augmentation outcomes over a 20 -year period. ${ }^{18}$ The review included 74 studies (including one level I) of vertebroplasty for osteoporotic compression fractures, 35 kyphoplasty studies for osteoporotic fractures, and 18 studies for tumorrelated fractures, which were all level IV studies. The authors found level I evidence that vertebroplasty provides superior pain control over medical management in the first 2 weeks, and level II-III evidence that within the first 3 months there are superior outcomes in analgesic use, disability, and general health, and finally level II-III evidence that by 2 years there is a similar level of pain control and physical function. With regards to kyphoplasty, there was level II-III evidence of improvement in daily activity, physical function, and pain control at 6 months, compared to medical management. Though the studies were favorable for tumor-related fractures there was insufficient evidence for comparison.

Since this review, other randomized trials have been performed, which have mostly shown improved pain control and physical function with vertebroplasty in the short term, ${ }^{59,60}$ but diminished or no difference with medical management at 1-year follow-up. ${ }^{60,61} \mathrm{~A}$ subsequent, larger, randomized controlled trial enrolling 202 patients dubbed VERTOS II did find sustained, significant differences at 1-year follow-up with continued improved pain relief for the vertebroplasty group. ${ }^{62}$

Notably, in 2009, two double-blind randomized controlled trials were published in the New England Journal of
Medicine $e^{63,64}$ and received significant publicity. These studies, by Buchbinder et al and by Kallmes et al, involved comparisons between vertebroplasty and sham procedure groups, rather than the usual comparison group of medical management. The authors of both studies reported no difference in pain control or function between the groups, from 1 week to 6 months follow-up in one study and 1 month follow-up in the other. ${ }^{63,64}$ They suggested that the benefits of vertebroplasty in prior trials were secondary to a procedural placebo effect. ${ }^{65,66}$ These studies have been the subject of criticism, focusing on their low enrollment numbers (78 and 131 patients), low volume and infrequent rate of vertebroplasty performed at the centers over a long time interval, lack of clear inclusion criteria specifying patients with mechanical axial back pain, and inadequate volume of cement injection. ${ }^{67,68}$ The debate about vertebral augmentation continues. One ongoing study that may shed light on the matter is the VERTOS IV trial, a non-industry supported, prospective randomized controlled trial of 180 patients that compares vertebroplasty to sham procedure, similar to the New England Journal of Medicine studies, but uses the strict inclusion criteria of the VERTOS II trial. ${ }^{69,70}$

\section{Conclusion}

Vertebral fractures have significant effect on patient quality of life and a high socioeconomic cost. Initial management begins with the primary care provider. Diagnostic studies include plain radiographs and are typically followed by bone density workup with DEXA imaging. Conservative management should be attempted for up to 6 weeks. This may involve 
coordination with other providers including endocrinologists, physical therapists, and possibly pain specialists. Medical therapy should be aimed at pain control, early mobilization with the assistance of bracing and rehabilitation, and improving bone quality with the goal of future fracture prevention. If patients remain refractory to conservative treatment of their pain, or develop worsening of their fracture on subsequent imaging, a referral to a spine surgeon or pain interventionalist may be appropriate. Vertebroplasty and kyphoplasty are low-risk procedures that significantly improve pain relief and physical function. Though evidence for their efficacy in oncologic fractures is limited, a large number of studies have shown at least short-term efficacy in improving pain and physical function for the more common osteoporotic fractures. These varied therapeutic modalities allow for the comprehensive acute and long-term management for patients suffering from vertebral compression fractures.

\section{Disclosure}

Dr McGirt receives research support from Stryker and Depuy and is a consultant for TranS1. Dr Wong has no conflicts of interest to declare in this work.

\section{References}

1. Ensrud KE, Schousboe JT. Clinical practice. Vertebral fractures. NEngl J Med. 2011;364(17):1634-1642.

2. Fink HA, Milavetz DL, Palermo L, et al. What proportion of incident radiographic vertebral deformities is clinically diagnosed and vice versa? J Bone Miner Res. 2005;20(7):1216-1222.

3. Francis RM, Baillie SP, ChuckAJ, et al. Acute and long-term management of patients with vertebral fractures. QJM. 2004;97(2):63-74.

4. Cooper C. Epidemiology and public health impact of osteoporosis. Baillieres Clin Rheumatol. 1993;7(3):459-477.

5. Cauley JA, Palermo L, Vogt M, et al. Prevalent vertebral fractures in black women and white women. J Bone Miner Res. 2008;23(9):1458-1467.

6. Ling X, Cummings SR, Mingwei Q, et al. Vertebral fractures in Beijing, China: the Beijing Osteoporosis Project. J Bone Miner Res. 2000; 15(10):2019-2025.

7. Riggs BL, Melton LJ 3rd. Involutional osteoporosis. $N$ Engl J Med. 1986;314(26):1676-1686.

8. Riggs BL, Wahner HW, Melton LJ 3rd, Richelson LS, Judd HL, Offord KP. Rates of bone loss in the appendicular and axial skeletons of women. Evidence of substantial vertebral bone loss before menopause. J Clin Invest. 1986;77(5):1487-1491.

9. Sinaki M. Exercise for patients with osteoporosis: management of vertebral compression fractures and trunk strengthening for fall prevention. $P M \& R$. 2012;4(11):882-888.

10. Nevitt MC, Cummings SR, Stone KL, et al. Risk factors for a firstincident radiographic vertebral fracture in women $>$ or $=65$ years of age: the study of osteoporotic fractures. J Bone Miner Res. 2005;20(1): $131-140$

11. Melton LJ 3rd, Lane AW, Cooper C, Eastell R, O'Fallon WM, Riggs BL. Prevalence and incidence of vertebral deformities. Osteoporos Int. 1993;3(3):113-119.

12. O’Neill TW, Felsenberg D, Varlow J, Cooper C, Kanis JA, Silman AJ. The prevalence of vertebral deformity in european men and women: the European Vertebral Osteoporosis Study. J Bone Miner Res. 1996; 11(7):1010-1018.
13. Compston JE. Risk factors for osteoporosis. Clin Endocrinol (Oxf). 1992;36(3):223-224.

14. Schousboe JT, DeBold CR, Bowles C, Glickstein S, Rubino RK. Prevalence of vertebral compression fracture deformity by X-ray absorptiometry of lateral thoracic and lumbar spines in a population referred for bone densitometry. J Clin Densitom. 2002;5(3):239-246.

15. Jergas M, Genant HK. Spinal and femoral DXA for the assessment of spinal osteoporosis. Calcif Tissue Int. 1997;61(5):351-357.

16. Ross PD, Davis JW, Epstein RS, Wasnich RD. Pre-existing fractures and bone mass predict vertebral fracture incidence in women. Ann Intern Med. 1991;114(11):919-923.

17. Lindsay R, Silverman SL, Cooper C, et al. Risk of new vertebral fracture in the year following a fracture. JAMA. 2001;285(3):320-323.

18. McGirt MJ, Parker SL, Wolinsky JP, Witham TF, Bydon A, Gokaslan ZL. Vertebroplasty and kyphoplasty for the treatment of vertebral compression fractures: an evidenced-based review of the literature. Spine J. 2009;9(6):501-508.

19. Truumees E. Osteoporosis. Spine (Phila Pa 1976). 2001;26(8): 930-932.

20. Etzioni DA, Liu JH, Maggard MA, Ko CY. The aging population and its impact on the surgery workforce. Ann Surg. 2003;238(2):170-177.

21. Dolan P, Torgerson DJ. The cost of treating osteoporotic fractures in the United Kingdom female population. Osteoporos Int. 1998; 8(6):611-617.

22. Cooper C, Atkinson EJ, Jacobsen SJ, O'Fallon WM, Melton LJ 3rd. Population-based study of survival after osteoporotic fractures. Am J Epidemiol. 1993;137(9):1001-1005.

23. Nakai Y, Noth R, Wexler J, Volpp B, Tsodikov A, Swislocki A. Computerbased screening of chest $\mathrm{X}$-rays for vertebral compression fractures as an osteoporosis index in men. Bone. 2008;42(6):1214-1218.

24. Kavanagh M, Walker J. Assessing and managing patients with cauda equina syndrome. Br J Nurs. 2013;22(3):134-137.

25. Adami S, Gatti D, Rossini M, et al. The radiological assessment of vertebral osteoporosis. Bone. 1992;13(Suppl 2):S33-S36.

26. Lenchik L, Rogers LF, Delmas PD, Genant HK. Diagnosis of osteoporotic vertebral fractures: importance of recognition and description by radiologists. AJR Am J Roentgenol. 2004;183(4):949-958.

27. Kim JH, Kim JI, Jang BH, Seo JG. The comparison of bone scan and MRI in osteoporotic compression fractures. Asian Spine J. 2010; 4(2):89-95.

28. Bavry AA, Khaliq A, Gong Y, Handberg EM, Cooper-Dehoff RM, Pepine CJ. Harmful effects of NSAIDs among patients with hypertension and coronary artery disease. Am J Med. 2011;124(7):614-620.

29. Dodwell ER, Latorre JG, Parisini E, et al. NSAID exposure and risk of nonunion: a meta-analysis of case-control and cohort studies. Calcif Tissue Int. 2010;87(3):193-202.

30. Longo UG, Loppini M, Denaro L, Maffulli N, Denaro V. Conservative management of patients with an osteoporotic vertebral fracture: a review of the literature. J Bone Joint Surg Br. 2012;94(2):152-157.

31. Knopp JA, Diner BM, Blitz M, Lyritis GP, Rowe BH. Calcitonin for treating acute pain of osteoporotic vertebral compression fractures: a systematic review of randomized, controlled trials. Osteoporos Int. 2005;16(10):1281-1290.

32. Rovetta G, Maggiani G, Molfetta L, Monteforte P. One-month follow-up of patients treated by intravenous clodronate for acute pain induced by osteoporotic vertebral fracture. Drugs Exp Clin Res. 2001; 27(2):77-81.

33. Nevitt MC, Chen P, Kiel DP, et al. Reduction in the risk of developing back pain persists at least 30 months after discontinuation of teriparatide treatment: a meta-analysis. Osteoporos Int. 2006;17(11):1630-1637.

34. Nevitt MC, Chen P, Dore RK, et al. Reduced risk of back pain following teriparatide treatment: a meta-analysis. Osteoporos Int. 2006; 17(2):273-280.

35. Hongo M, Miyakoshi N, Shimada Y, Sinaki M. Association of spinal curve deformity and back extensor strength in elderly women with osteoporosis in Japan and the United States. Osteoporos Int. 2012; 23(3):1029-1034. 
36. Sinaki M, Nwaogwugwu NC, Phillips BE, Mokri MP. Effect of gender, age, and anthropometry on axial and appendicular muscle strength. Am J Phys Med Rehabil. 2001;80(5):330-338.

37. Miyakoshi N, Hongo M, Maekawa S, Ishikawa Y, Shimada Y, Itoi E. Back extensor strength and lumbar spinal mobility are predictors of quality of life in patients with postmenopausal osteoporosis. Osteoporos Int. 2007;18(10):1397-1403.

38. Chen JH, Liu C, You L, Simmons CA. Boning up on Wolff's Law: mechanical regulation of the cells that make and maintain bone. $J$ Biomech. 2010; 43(1):108-18.

39. Sinaki M, Mikkelsen BA. Postmenopausal spinal osteoporosis: flexion versus extension exercises. Arch Phys Med Rehabil. 1984; 65(10):593-596.

40. Sinaki M. Yoga spinal flexion positions and vertebral compression fracture in osteopenia or osteoporosis of spine: case series. Pain Pract. 2013;13(1):68-75

41. Sinaki M. Critical appraisal of physical rehabilitation measures after osteoporotic vertebral fracture. Osteoporos Int. 2003;14(9):773-779.

42. Sinaki M. The role of physical activity in bone health: a new hypothesis to reduce risk of vertebral fracture. Phys Med Rehabil Clin NAm. 2007; 18(3):593-608, xi-xii.

43. Sinaki M, Itoi E, Wahner HW, et al. Stronger back muscles reduce the incidence of vertebral fractures: a prospective 10 year follow-up of postmenopausal women. Bone. 2002;30(6):836-841.

44. Sinaki M, Brey RH, Hughes CA, Larson DR, Kaufman KR. Significant reduction in risk of falls and back pain in osteoporotic-kyphotic women through a Spinal Proprioceptive Extension Exercise Dynamic (SPEED) program. Mayo Clin Proc. 2005;80(7):849-855.

45. Malmros B, Mortensen L, Jensen MB, Charles P. Positive effects of physiotherapy on chronic pain and performance in osteoporosis. Osteoporos Int. 1998;8(3):215-221.

46. Bennell KL, Matthews B, Greig A, et al. Effects of an exercise and manual therapy program on physical impairments, function and quality-of-life in people with osteoporotic vertebral fracture: a randomised, single-blind controlled pilot trial. BMC Musculoskelet Disord. 2010;11:36.

47. Papaioannou A, Adachi JD, Winegard K, et al. Efficacy of home-based exercise for improving quality of life among elderly women with symptomatic osteoporosis-related vertebral fractures. Osteoporos Int. 2003;14(8):677-682.

48. Pfeifer M, Begerow B, Minne HW. Effects of a new spinal orthosis on posture, trunk strength, and quality of life in women with postmenopausal osteoporosis: a randomized trial. Am J Phys Med Rehabil. 2004;83(3):177-186.

49. Lantz SA, Schultz AB. Lumbar spine orthosis wearing. II. Effect on trunk muscle myoelectric activity. Spine (Phila Pa 1976). 1986; 11(8):838-842.

50. Waters RL, Morris JM. Effect of spinal supports on the electrical activity of muscles of the trunk. J Bone Joint Surg Am . 1970;52(1):51-60.

51. Tuong NH, Dansereau J, Maurais G, Herrera R. Three-dimensional evaluation of lumbar orthosis effects on spinal behavior. $J$ Rehabil Res Dev. 1998;35(1):34-42.

52. Gangi A, Guth S, Imbert JP, Marin H, Dietemann JL. Percutaneous vertebroplasty: indications, technique, and results. Radiographics. 2003;23(2):e10.

53. Mukherjee S, Lee Y-P. Current Concepts in the Management of Vertebral Compression Fractures. Operative Techniques in Orthopaedics. 2011; 21(3):251-260.

Journal of Multidisciplinary Healthcare

\section{Publish your work in this journal}

The Journal of Multidisciplinary Healthcare is an international, peerreviewed open-access journal that aims to represent and publish research in healthcare areas delivered by practitioners of different disciplines. This includes studies and reviews conducted by multidisciplinary teams as well as research which evaluates the results or conduct of such teams or Submit your manuscript here: http://www.dovepress.com/journal-of-multidisciplinary-healthcare-journal
54. Truumees E, Hilibrand A, Vaccaro AR. Percutaneous vertebral augmentation. Spine J. 2004;4(2):218-229.

55. Syed MI, Jan S, Patel NA, Shaikh A, Marsh RA, Stewart RV. Fatal fat embolism after vertebroplasty: identification of the high-risk patient. AJNR Am J Neuroradiol. 2006;27(2):343-345.

56. Lin WC, Cheng TT, Lee YC, et al. New vertebral osteoporotic compression fractures after percutaneous vertebroplasty: retrospective analysis of risk factors. J Vasc Interv Radiol. 2008;19(2 Pt 1): 225-231.

57. Taylor RS, Fritzell P, Taylor RJ. Balloon kyphoplasty in the management of vertebral compression fractures: an updated systematic review and meta-analysis. Eur Spine J. 2007;16(8):1085-1100.

58. Hadley C, Awan OA, Zoarski GH. Biomechanics of vertebral bone augmentation. Neuroimaging Clin N Am. 2010;20(2):159-167.

59. Voormolen MH, Mali WP, Lohle PN, et al. Percutaneous vertebroplasty compared with optimal pain medication treatment: short-term clinical outcome of patients with subacute or chronic painful osteoporotic vertebral compression fractures. The VERTOS study. AJNR Am J Neuroradiol. 2007;28(3):555-560.

60. Wardlaw D, Cummings SR, Van Meirhaeghe J, et al. Efficacy and safety of balloon kyphoplasty compared with non-surgical care for vertebral compression fracture (FREE): a randomised controlled trial. Lancet. 2009;373(9668):1016-1024.

61. Rousing R, Hansen KL, Andersen MO, Jespersen SM, Thomsen K, Lauritsen JM. Twelve-months follow-up in forty-nine patients with acute/semiacute osteoporotic vertebral fractures treated conservatively or with percutaneous vertebroplasty: a clinical randomized study. Spine (Phila Pa 1976). 2010;35(5):478-482.

62. Klazen CA, Lohle PN, de Vries J, et al. Vertebroplasty versus conservative treatment in acute osteoporotic vertebral compression fractures (Vertos II): an open-label randomised trial. Lancet. 2010; 376(9746):1085-1092.

63. Buchbinder R, Osborne RH, Ebeling PR, et al. A randomized trial of vertebroplasty for painful osteoporotic vertebral fractures. $N$ Engl J Med. 2009;361(6):557-568.

64. Kallmes DF, Comstock BA, Heagerty PJ, et al. A randomized trial of vertebroplasty for osteoporotic spinal fractures. N Engl J Med. 2009; 361(6):569-579.

65. Kallmes D, Buchbinder R, Jarvik J, et al. Response to "randomized vertebroplasty trials: bad news or sham news?". AJNR Am JNeuroradiol. 2009;30(10):1809-1810.

66. Miller FG, Kallmes DF, Buchbinder R. Vertebroplasty and the placebo response. Radiology. 2011;259(3):621-625.

67. Aebi M. Vertebroplasty: about sense and nonsense of uncontrolled "controlled randomized prospective trials". Eur Spine J. 2009; 18(9):1247-1248.

68. Noonan P. Randomized vertebroplasty trials: bad news or sham news? AJNR Am J Neuroradiol. 2009;30(10):1808-1809.

69. Asenjo JF, Rossel F. Vertebroplasty and kyphoplasty: new evidence adds heat to the debate. Curr Opin Anaesthesiol. 2012;25(5):577-583.

70. Firanescu C, Lohle PN, de Vries J, et al. A randomised sham controlled trial of vertebroplasty for painful acute osteoporotic vertebral fractures (VERTOS IV). Trials. 2011;12:93.

healthcare processes in general. The journal covers a wide range of areas and welcomes submission from practitioners at all levels, from all over the world. The manuscript management system is completely online and includes a very quick and fair peer-review system. Visit http://www.dovepress.com/testimonials.php to read real quotes from published authors. 